\title{
La gestión de intangibles en la Dirección de Comunicación Corporativa. Estudio sobre el DirCom en las organizaciones de Reino Unido
}

\section{The intangibles management in the Corporate Communication Department. Study about the DirCom in UK organisations}

Cristina González Oñate. Universitat Jaume I

Patricia Monleón López. Universitat Jaume I

Recibido: 7-V-2013 - Aceptado: 26-VII-2013

Resumen:

En las últimas décadas se ha consolidado la figura del Director de Comunicación (DirCom) en las organizaciones europeas, sobre todo, en Reino Unido. El nuevo entorno socio-económico exige una redefinición de la figura y una potenciación de las funciones referentes a la gestión de intangibles sobre otras tareas clásicas y arraigadas en el DirCom. Los intangibles empresariales son factores que funcionan en el entorno competitivo actual y, la Comunicación Corporativa, la disciplina estratégica idónea para su gestión. En este trabajo se presentan los resultados más significativos de una investigación realizada sobre el estado de la gestión de los intangibles empresariales dentro de las Direcciones de Comunicación Corporativa de Reino Unido.

Palabras clave:

Dircom; Reino Unido; investigación; Corporate; gestión; intangibles.

Abstract:

In recent decades progress in and the consolidation of the figure of the Director of Communication (DirCom) have been achieved in european organisations, particularly in the United Kingdom. The new socio-economic setting expects the DirCom figure to be redefined, and tasks relating to intangibles management to be reinforced more than other classical and more typical tasks for the DirCom. Business intangibles are factors which operate in the competitive setting, and Corporate Communication has become an ideal strategic discipline to manage them. This work presents the most significant results obtained in the research work conducted into the state of managing intangibles in UK Corporate Communication Managements.

Keywords:

Dircom; United Kingdom; research; Corporate; management; intangibles. 


\section{Introducción}

En el fin de la primera década del siglo XXI en la que nos encontramos, con la consolidación generalizada en el primer mundo del capitalismo y la Economía de mercado, las empresas tienen que responder, para su supervivencia y progreso, a los cambios que se dan en este nuevo contexto. Todo cambio, interno o externo, afecta a las organizaciones y exige que estas respondan a través de decisiones, en las formas de relacionarse, de actuar, o gestionar (Costa, 1999: 23).

La empresa, en este nuevo entorno, ya no puede ser entendida como un agente de producción, sino que debe actuar como agente social, esto es, constituirse como institución. Institución entendida como organización que, aparte de buscar fines económicos, tiene múltiples y visibles responsabilidades sociales, exigidas por todos los públicos a los que afecta.

Las organizaciones que consideren a sus públicos como sujetos de opinión y no como sujetos de consumo en la nueva realidad social y geopolítica, serán las que ganen en credibilidad (Pizzolante, 2009: 56).

Como además propone López Lita (2000: 43), la empresa tiene que ser considerada como una organización comunicativa, ya que la competitividad de las organizaciones no tiene que ver únicamente con la productividad, sino también con la relación de las organizaciones con sus distintos públicos. Una organización comunicativa implica un nuevo modelo de empresa en el que la Comunicación Corporativa asume un papel fundamental y en el que se debe perseguir el objetivo gemelo para la supervivencia: el liderazgo en comunicación (con una imagen potente y una marca conocida) y el liderazgo en costes (con productos o servicios líderes en precio). De hecho, como ya reflexionaba López Lita (1999: 52) en su obra anterior, la Comunicación Corporativa forma parte de una nueva concepción de empresa, donde la empresa es en sí misma un sistema de comunicación especializado en su propio crecimiento. Así, la Comunicación Corporativa, junto con la gestión financiera, la gestión de recursos humanos o la gestión de producción, se constituye como otra área más para contribuir al logro de los objetivos de las organizaciones (Van Riel, 1997: 75).

Hay que tener en cuenta que la Sociedad capitalista ha pasado por varias etapas en la gestión empresarial. Como desarrolla Costa (1999: 53), durante años, y desde la Revolución industrial del siglo XX, la Sociedad, basada en el intercambio de objetos materiales, se ha asentado en la teoría de Adam Smith de organización de la producción y división del trabajo. En esta Sociedad, las relaciones de comunicación fueron excluidas por la primacía de las relaciones de producción. Es por esto que las teorías clásicas del management se consolidaron como forma de jerarquizar y administrar el mando para una mejor coordinación y control de la producción. Posteriormente, los conceptos surgidos en los años veinte de marketing, relaciones humanas o dirección por objetivos, con la aparición de la planificación y la calidad total, desembocan en lo que Costa denomina management a la europea, que se contrapone a la visión estadounidense de planificación racional de la producción y aboga por aplicar la psicología y la sociología para considerar en mayor grado las interacciones humanas, los grupos de trabajo y, entre ellos y por primera vez, la Comunicación Corporativa. 
De esta forma, en los últimos años se ha hecho evidente el paso de una Sociedad basada en la producción de objetos a una Sociedad en que la comunicación e intercambio de símbolos es nuestra actividad central. En esta Sociedad de la Comunicación, las organizaciones se establecen como agrupaciones de personas que realizan funciones básicas mediante relaciones fundamentalmente comunicativas (Martín, 2010: 24). En consecuencia, cada vez se ha hecho más intensa una conciencia de comunicación en el mundo de las empresas donde la Comunicación Corporativa es el instrumento destinado a resolver situaciones y problemas nuevos, cada vez más complejos y de los que no se disponía de modelos de razonamiento ni herramientas de acción específicas (Costa, 2003: 27).

En conclusión, como declara Eco, (2010: 32), los sistemas de comunicación se han constituido en el negocio más importante de nuestra época.

Ante esta nueva situación es necesario que la Comunicación Corporativa, ya como disciplina consolidada, sea gestionada desde y en cualquier tipo de agente.

Además, en la actualidad, nos encontramos en un estado socioeconómico donde priman más los símbolos sobre los productos y servicios en sí mismos. Hoy en día estamos en la encrucijada de una nueva conciencia internacional en torno a los activos inmateriales, el denominado movimiento de intangibles (Cañibano y Sánchez, 2004: 62). Fruto de su importancia económica y social, recientemente están aflorando investigaciones en materia de intangibles y está creciendo el interés en las empresas por su aplicación.

En este nuevo entorno, los activos intangibles (AI) y recursos intangibles (RI), cuando son gestionados desde el campo de la Comunicación Corporativa, generan valor y se constituyen en verdaderos regentes y condicionantes de las dinámicas entre las organizaciones y el resto de agentes de su entorno. Sin embargo, las investigaciones sobre la relación entre Comunicación Corporativa e intangibles son todavía escasas, y ello requiere un esfuerzo investigador desde el campo de las Ciencias de la Comunicación.

Este trabajo está basado en una investigación sobre la gestión de intangibles desde la perspectiva de la Dirección de Comunicación, como disciplina integrada en las Ciencias de la Comunicación, y desde una visión más internacional.

\section{Objetivos y metodología de la investigación}

El presente trabajo cubre los siguientes objetivos de investigación:

Enmarcar la gestión de intangibles en el contexto de la Comunicación Corporativa y la Dirección de Comunicación Corporativa. 
- Conocer el estado actual de la función gestión de intangibles en la práctica profesional del Director de Comunicación Corporativa en Reino Unido.

- $\quad$ Aproximarse a las tendencias en materia de gestión de intangibles y Dirección de Comunicación Corporativa en Reino Unido.

Con el primer objetivo, se pretende revisar el papel de la Comunicación en las organizaciones hasta el surgimiento en Europa de la figura del Director de Comunicación (DirCom) y su última evolución: la de la gestión profesional de los intangibles de la Comunicación. Con el segundo objetivo, se quiere conocer el grado de consideración de la gestión de intangibles dentro de las Direcciones de Comunicación Corporativa de Reino Unido, y por tanto, su integración en las funciones del DirCom. En definitiva, se trata de conocer cuál es la relación entre el DirCom y los intangibles empresariales en este país. Con el tercer y último objetivo, se busca detectar las últimas tendencias entre los profesionales del Reino Unido en materia de Dirección de Comunicación Corporativa.

La estructura seleccionada en la presente investigación cualitativa está compuesta por dos fases: una primera fase de naturaleza exploratoria y una segunda fase de carácter conclusivo.

Fase I. Exploratoria. La fase exploratoria se compone a su vez de dos etapas:

a) Marco teórico: Revisión bibliográfica y documental. En este apartado, se ha realizado una búsqueda y análisis de libros, investigaciones, artículos, tesis y cualquier documento o información relacionada con los siguientes ámbitos de estudio:

- $\quad$ Relaciones Públicas y Comunicación Corporativa.

- $\quad$ Dirección de Comunicación Corporativa y figura profesional del DirCom.

- $\quad$ Gestión de intangibles en relación con el ámbito de la Comunicación Corporativa.

b) Marco empírico: Entrevistas personales. Confección de un guión de preguntas para realizar las entrevistas a Directores de Comunicación de organizaciones de Reino Unido.

La metodología cualitativa seleccionada para la investigación empírica ha sido la de las entrevistas personales es su modalidad estructurada, pues se persiguen unos ítems concretos a investigar. Los ítems a investigar han sido previamente delimitados según los objetivos de investigación. 
Cuadro 1. Ítems a investigar basándose en los objetivos de la investigación

\begin{tabular}{|c|c|c|}
\hline Planteamientos & Ítems a investigar & Objetivos de la investigación \\
\hline P1 & $\begin{array}{l}\text { Perfil del Director de Comunicación } \\
\text { en Reino Unido }\end{array}$ & \multirow{4}{*}{$\begin{array}{l}\text { O1. Enmarcar la gestión de intangibles en el } \\
\text { contexto de la Comunicación Corporativa y } \\
\text { la Dirección de Comunicación Corporativa. } \\
\text { O2. Conocer el estado actual de la función } \\
\text { gestión de intangibles en la práctica } \\
\text { profesional del Director de Comunicación } \\
\text { Corporativa en Reino Unido. }\end{array}$} \\
\hline $\mathbf{P 2}$ & $\begin{array}{l}\text { El Director de Comunicación en } \\
\text { Reino Unido como figura estratégica }\end{array}$ & \\
\hline $\mathbf{P 3}$ & $\begin{array}{l}\text { Relación Comunicación e Intangibles } \\
\text { en la DirCom de Reino Unido }\end{array}$ & \\
\hline $\mathbf{P 4}$ & $\begin{array}{l}\text { El DirCom de Reino Unido como } \\
\text { gestor de intangibles }\end{array}$ & \\
\hline P5 & $\begin{array}{lll}\text { Tendencias } & \text { en } & \text { Dirección } \\
\text { Comunicación en Reino Unido }\end{array}$ & $\begin{array}{l}\text { O3. Aproximarse a las tendencias en materia } \\
\text { de gestión de intangibles y Dirección de } \\
\text { Comunicación Corporativa en Reino Unido. }\end{array}$ \\
\hline
\end{tabular}

Fuente: Elaboración propia.

El guión de preguntas para la entrevista ha surgido a partir de las conclusiones y reflexiones obtenidas en el marco teórico.

Cuadro 2. Guión de preguntas para la entrevista

\section{Planteamiento $n^{0} 1$}

PERFIL DIRCOM EN RU

1. ¿Cómo definiría lo que es un Director de Comunicación?, ¿cuáles considera que son sus principales funciones?

2. ¿Cuál es la denominación completa de su cargo? ¿Está de acuerdo con esta denominación en relación con sus funciones y responsabilidades? ¿Piensa que en un futuro próximo esta denominación podría o debería de cambiar?

3. En caso de tener un Departamento de Comunicación a su cargo, ¿el departamento dispone de una estructura o desglose de funciones o personal para la gestión de intangibles específicos como la marca o la reputación o es usted el responsable directo de los mismos? 


\section{Planteamiento $\mathbf{n}^{\circ} 2$ \\ DIRCOM RU COMO FIGURA ESTRATÉGICA}

4. Como Director de Comunicación, ¿reporta formalmente a la Dirección general, CEO y/o la Presidencia de la empresa?, ¿considera que participa en el proceso de toma de decisiones estratégicas de la empresa? En caso afirmativo, ¿participa de algún modo en el desarrollo de la estrategia corporativa, por ejemplo, formando parte de la Junta o Comité de Dirección de la empresa?

5. ¿Trabaja bajo una estrategia de comunicación?, ¿la estrategia de comunicación está formalmente documentada?, ¿esta estrategia de comunicación deriva y está directamente relacionada con la estrategia corporativa/general de la empresa?

\section{Planteamiento $\mathbf{n}^{\mathbf{0} 3}$}

RELACIÓN COMUNICACIÓN E INTANGIBLES

6. Los expertos sugieren que la Comunicación Corporativa ha evolucionado hacia una gestión activa de intangibles como la marca y la reputación respecto a sus actividades tradicionales ¿está de acuerdo?

7. ¿Piensa que la comunicación es necesaria para que los intangibles generen valor o los intangibles generan valor por sí mismos?

8. ¿Considera que, para generar valor en la empresa, los intangibles deben formar parte del proceso de toma de decisiones de la empresa? ¿Deben los intangibles ser considerados en la formulación de la estrategia corporativa de la empresa? ¿Y en la formulación de la estrategia de comunicación?

\section{Planteamiento $n^{\circ} 4$}

DIRCOM RU COMO GESTOR DE INTANGIBLES

9. En la presente investigación los Recursos Intangibles (RI) clásicos en la Dirección de Comunicación son: la Identidad Corporativa, la Cultura corporativa y la Imagen Corporativa. Actualmente, como Director de Comunicación ¿se encarga usted de la gestión de cada uno de estos RI? ¿Alguno de estos RI forma parte de la formulación de la estrategia corporativa de su empresa? ¿Estos RI están contemplados en la estrategia de comunicación o en algún otro documento formal de su departamento? 
10. En la presente investigación los Activos Intangibles (AI) derivados de la Comunicación más comunes en la Dirección de Comunicación son: la Marca, la Responsabilidad Social Corporativa y la Reputación. Actualmente, como Director de Comunicación, ¿se encarga usted de la gestión de cada uno de estos AI?, ¿alguno de estos AI forma parte de la formulación de la estrategia corporativa de su empresa?, ¿estos AI están contemplados en la estrategia de comunicación o en algún otro documento formal de su departamento? ¿Dispone de planes o modelos específicos para su gestión como un programa de reputación o un plan de marca?

11. Atendiendo a la naturaleza y objetivos de su empresa, pueden existir otros RI y AI [que no sean los ya tratados], como por ejemplo el talento, la innovación o el liderazgo. Actualmente, ¿gestiona otros RI o AI anteriormente no contemplados? ¿Piensa que, como Director de Comunicación, debe ser usted responsable de todos los recursos y activos intangibles de la empresa o sólo de aquellos derivados de la Comunicación y su actividad? En su opinión, ¿el Director de Comunicación debe tener un amplio conocimiento de todo el abanico de RI y AI de la empresa para decidir estratégicamente cuáles comunicar?

12. En su caso particular, ¿podría afirmar que hay una efectiva integración de la gestión de intangibles en sus funciones como Director de Comunicación?

13. ¿Opina que puede hablarse de un Director de Comunicación de nueva generación para el que los intangibles son el centro de su gestión?, ¿piensa que esto es así en la mayoría de Direcciones de Comunicación en Reino Unido?

\section{Planteamiento $\mathrm{n}^{\circ} 5$}

TENDENCIAS DIRCOM EN REINO UNIDO

14. ¿Cuáles considera que son las principales tendencias globales en materia de Dirección de Comunicación?

En cuanto a la selección de la muestra se han establecido una serie de criterios para enmarcar el trabajo de campo. La muestra se compone de Directores de Comunicación de organizaciones de Reino Unido pertenecientes a diversos sectores de actividad. Uno de los criterios de calidad seguidos para la selección de las unidades de la muestra ha sido que, preferentemente, pero no de forma excluyente, los Directores de Comunicación seleccionados fueran miembros de la European Association of Communication Directors (EACD) en su sección de Reino Unido. De esta forma, se ha tratado de segmentar por perfil profesional y no por tamaño o tipología de organización, puesto que lo que interesa es conocer los 
aspectos prácticos y las opiniones en los profesionales, más allá de la naturaleza de la organización a la que pertenecen. Entre otros criterios preferentes, pero no excluyentes, para la selección de la muestra también ha estado la pertenencia a la European Association of Communication Directors (EACD) en su sección de Reino Unido o a cualquier otra organización legitimada en el país relacionada con la Comunicación Corporativa.

De este modo, se ha realizado un total de doce entrevistas personales a Directores de Comunicación Corporativa de importantes organizaciones del Reino Unido entre las que están Barclays, $B P, P w C$, BritishTelecomm, National Health Service (NHS), Rolls-Royce, University of Nottingham, entre otras.

Por último, una vez realizadas, se ha procedido a la traducción de las respuestas del inglés al español con el objetivo de facilitar la interpretación posterior.

Fase II. Conclusiva. Una vez cerrada la fase exploratoria, se han obtenido las conclusiones finales con las reflexiones a partir de la combinación de las conclusiones del marco teórico y las conclusiones del trabajo de campo. Con dichas conclusiones, se ha adquirido información de tipo cualitativo.

\section{La Dirección de Comunicación Corporativa y el Dircom en Europa y Reino Unido}

La evolución de la gestión de intangibles en relación a la Dirección de Comunicación Corporativa ha pasado por varias fases $^{1}$ : una primera de desconocimiento del concepto "intangibles" y donde había una primacía del concepto marca, una segunda fase de emergencia, con la paulatina consideración de los intangibles en algunas Direcciones de Comunicación, y una más reciente de inicios de integración de la gestión de intangibles en la Dirección de Comunicación Corporativa de las organizaciones.

En el plano teórico, ha emergido una nueva generación de Directores de Comunicación cuya tarea principal está fundamentada en la gestión de intangibles. El DirCom tendrá que basar la Comunicación Corporativa en los intangibles empresariales y gestionar también los intangibles que son de su competencia. Como ejemplo, en España, en el último estudio realizado sobre el DirCom por la EOI, los Directores de Comunicación gestionan intangibles pero no son conscientes de la función global "gestión de intangibles".

En la actualidad, la figura del DirCom goza de una posición completamente consolidada en Europa y, además, ya se está extendiendo fuera del continente europeo sobre todo en países en desarrollo y en economías emergentes (Costa, 2011: 2425).

1 Clasificación hecha a partir de la realización de un análisis comparativo de todos los informes publicados en la última década por Villafañe (Dir.) (2000-2011): "La comunicación empresarial y la gestión de los intangibles en España y Latinoamérica. Informe anual". 
Con anterioridad a la concepción actual de Dirección de Comunicación, se desarrolló la teoría y práctica de las relaciones públicas.

La teoría de las relaciones públicas propone una nueva forma de entender las organizaciones como instituciones insertadas en una Sociedad y, en consecuencia, con unas necesidades comunicativas con sus públicos (Grunig y Hunt, 2003), (Black, 2004), (Cutlip, Center y Broom, 2000).

Sin embargo, aunque las relaciones públicas fueron capaces de explicar las bases de la Comunicación Corporativa, han actuado de forma fragmentaria, abordando acciones concretas, sin tener en cuenta otras áreas de la empresa y con una falta de concepción integral de la organización (Sotelo, 2001). De esta forma, las Relaciones Públicas en las organizaciones han tenido que ir evolucionando hasta llegar a un concepto global de Comunicación Corporativa que sea válido para el desempeño de las organizaciones en el complejo entorno actual.

En el caso de Reino Unido, la historia moderna de la Comunicación, como analiza Koper (Koper en Van Ruler y Vercic, 2004: 467-485), comienza a mediados del siglo XX cuando emerge una fuerte cultura popular mediática en el país que culmina a final de siglo con medios de comunicación emblemáticos como la cadena de televisión $B B C$ y el diario The Sun. Además, en estas décadas, esta nación se constituye en sí misma como una fuerte marca-país con la potenciación de la reputación de sus Universidades, sus internacionales figuras musicales o sus renombrados científicos y autores literarios, constituyéndose en el segundo país más conocido del mundo después de los Estados Unidos de América.

Pero, en concreto, como aporta Davis (2002: 47-50), el crecimiento de las relaciones públicas en Reino Unido tiene lugar a partir de la década de 1980 cuando los distintos agentes (gobiernos, empresas, sindicatos, etc.), fruto de la política de libre mercado, el avance de la pobreza, la inseguridad de los trabajadores, y la privatización y desregulación de muchos sectores de actividad, tienen que requerir rápidamente de las relaciones públicas para lograr el soporte de sus públicos. Esta etapa, bajo el Gobierno de la Primera Ministra Margaret Thatcher, fue de gran expansión de las relaciones públicas por lo que el teórico denomina la triple alianza y que supuso el trabajo conjunto entre gobierno, empresas y las industrias de relaciones públicas. De hecho, fue en esta época cuando las principales empresas británicas de relaciones públicas, entre las que estaban Shandwick, Lowe-Bell o Dewe-Rogerson, alcanzaron el top ten de la totalidad de industrias de Reino Unido.

Como también aportan Dinan y Miller (European Journal of Communication, 2000, nº15: 5-35), las relaciones públicas en Reino Unido tienen un importante crecimiento en la etapa del Gobierno Thatcher, es decir, desde 1979 y durante la década de los noventa, cuando el sector de la consultoría de relaciones públicas y la Comunicación en las organizaciones se expanden por su importante papel y función en la apertura de los mercados y la desregulación y la privatización de muchas empresas. 
Por tanto, la historia de la Comunicación en Reino Unido comienza con el uso y aplicación de la teoría norteamericana de las relaciones públicas para objetivos principalmente políticos desde 1979, y con extensión en la década de los ochenta y noventa del pasado siglo, donde hay un fuerte crecimiento y avance de empresas especializadas en relaciones públicas y la creación de departamentos en las propias empresas.

De este modo, y como analizan White, L'Etang y Moss (Sriramesh y Vercic, 2009: 715-735), la historia de las relaciones públicas en Reino Unido es particular por su contexto cultural, por lo que no existe en este país una progresión clara de las relaciones públicas como lo ha habido en Estados Unidos.

Por tanto, no habrá un desarrollo teórico de la Comunicación Corporativa desde su concepción global hasta ya bien entrado el siglo XXI a través de teóricos como Kitchen y Schultz (2001), Gregory (2004), Oliver (2010), o Cornelissen (2011).

En relación al estado actual de la Comunicación Corporativa en Reino Unido (Koper en Van Ruler y Vercic, 2004: 467-485), el trabajo se desarrolla mayoritariamente en las consultoras y en los departamentos propios de las empresas. En el caso de los departamentos, la tarea del profesional consiste en trabajar al servicio de los intereses de la empresa y los perfiles más usuales giran en torno a puestos tácticos, como agentes de prensa o relacionistas públicos, o puestos senior como "director of communication" (Director de Comunicación) o "head of public relations" (Jefe de Relaciones Públicas). En el caso de las consultoras, los profesionales de la Comunicación suelen trabajar con muchos clientes dispares. Por otra parte, la inversión y apuesta por la Comunicación Corporativa está muy avanzada en el sector público y en el sistema nacional de Sanidad (National Health Service-NHS) y los núcleos en gestión de Comunicación se encuentran en las ciudades de Londres y Manchester. En definitiva, aunque existen denominaciones que hacen referencia a funciones particulares de la Comunicación Corporativa como "public affairs" (asuntos públicos) o "crisis management” (gestión de crisis), se está haciendo extensivo en Reino Unido el uso de la denominación global de "Comunicación Corporativa” para referirse a la práctica profesional y en relación a funciones de dirección estratégica.

De hecho, si atendemos a los resultados de la muestra específica de Reino Unido, compuesta por más de 200 profesionales en el estudio europeo del European Communication Monitor de sus ediciones 2011 y 2012 (VV.AA., 2011: 56-57 y 2012: 63-67), actualmente, las principales características de la Dirección de Comunicación en Reino Unido tienen que ver con el concepto global de Comunicación Corporativa y con funciones estratégicas:

- $\quad$ Área que se denomina en igual medida entre los términos “Corporate Communication” (Comunicación Corporativa) o "Strategic Communication" (Comunicación estratégica).

- $\quad$ El nivel de dependencia y relación directa con la Dirección general de la empresa está en torno al 70\% de los casos (de los cuales aproximadamente un $20 \%$ pertenecen a la Junta Directiva y un $45 \%$ reporta directamente al CEO), dato que, aunque elevado, está por debajo de la media europea (84\%). Se trata de un área que gestiona tres o más 
tipologías de Comunicación en el $90 \%$ de los casos, muy por encima de la media europea (80\%), por lo que se trata de una Comunicación muy global.

- Las Direcciones de Comunicación de Reino Unido, junto a las de Suiza, son las primeras en la gestión de los social media, considerada por todos los DirCom europeos área de mayor crecimiento futuro en las empresas. Un 61,1\% usan códigos éticos en su desempeño profesional, muy por encima de la media de Europa y solo por detrás de Bélgica.

- $\quad$ Solo para un 34,4\% de los profesionales su función tiene una orientación operativa, por debajo de la media europea y solo por detrás de Italia. Por lo que, para $30 \%$ su función se basa en una gestión de las actividades de Comunicación, para un $15 \%$ la formación de los miembros en la misión y visión de la empresa y ya para un $20 \%$ (más que en la media europea) su función es la de alinear la Comunicación con la organización y los públicos estratégicos.

- $\quad$ El 78,2\% de los profesionales consideran que tienen una influencia ejecutiva en la planificación de los negocios muy por encima de la media europea y solo por detrás de Finlandia y Alemania. Del mismo modo, para un 73,2\% influyen en materia de asesoramiento, también por encima de la media europea y solo por detrás de Alemania, Noruega y Holanda.

\section{Comunicación Corporativa y gestión de intangibles}

Como varios autores señalan (García Perdiguero, 1993: 59), (Nevado y López, 2002: 63) o (Álvarez Plaza, 2005: 37), los intangibles son importantes factores para la competitividad de las empresas.

Los intangibles han sido factores intrínsecamente relacionados a la evolución de la Comunicación Corporativa. Como indica Matilla (2010: 3-24), con el fin del siglo XX, la Comunicación Corporativa pasa a ocupar un lugar estratégico en el mundo empresarial por la incorporación del concepto de intangibles como consecuencia del desarrollo de un nuevo escenario que precisa de un nuevo marco de actuación.

El Profesor Justo Villafañe (Villafañe 2006: 22) sintetiza en tres periodos el recorrido de la Comunicación Corporativa hasta llegar a la fase actual de gestión de intangibles:

1. Hegemonía de la comunicación de marketing. en la década de los ochenta y principios de los noventa, hay una prioridad de las relaciones informativas y la comunicación de marketing en las empresas lo que provoca un importante crecimiento de la publicidad. 
2. La emergencia de la imagen corporativa: en los noventa, comienza a haber un auge del concepto de Imagen Corporativa que corrobora cómo la inversión en comunicación corporativa es más rentable que la inversión en comunicación de producto.

3. La gestión de recursos intangibles: a comienzos de este siglo XXI hay una fuerte revalorización de los intangibles con la aparición del MERCO en 2001, el Foro de Reputación Corporativa o la creación del Instituto de Análisis de Intangibles en 2004.

De este modo, el protagonismo de los intangibles puede verse desde dos corrientes (Villafañe, 2005: 26):

1. Los procesos de generación de valor asociados a los intangibles en el management estratégico.

2. La evolución de la comunicación hacia el fortalecimiento de la marca, la imagen y la reputación corporativas (los intangibles).

En primer lugar, la Comunicación es un intangible en sí mismo que actúa de matriz del resto de intangibles. Pizzolante (1999: 65) considera que la Comunicación es en sí misma una transacción de valores. En el modelo de acción-comunicación propuesto por Costa (1999: 46), la Comunicación también es el vehículo que transporta los valores y, por tanto, la tarea de la Comunicación debe de centrarse en cómo seleccionar y combinar esos recursos. Como aporta López Lita (2005: 69) la identificación de activos intangibles es necesaria como soporte de la estrategia corporativa de las organizaciones y para que éstas dispongan de ventajas competitivas. Los activos intangibles generan valor en las empresas y también actúan como valor futuro para su supervivencia. Asimismo, añade el importante papel que tiene la Comunicación Corporativa y su profesional en dicho proceso.

Pérez (2008: 79) propone un modelo ideal de integración de los intangibles en el proceso de gestión de la Comunicación que supone el paso de una gestión instrumental y promocional de la Comunicación Corporativa, donde los activos intangibles son un área desvinculada de la Comunicación Corporativa, a un modelo directivo de gestión de la Comunicación donde "la comunicación es la madre de todos los intangibles” y, por primera vez, tendrá que gestionar y abarcar dichos intangibles.

Por tanto, la Dirección de Comunicación Corporativa de las organizaciones debe decidir estratégicamente qué intangibles gestiona y, a partir de aquí, influir, mediante la propia Comunicación Corporativa y su papel englobante, en los mismos.

Además, la Comunicación de los intangibles es un proceso necesario para que los intangibles generen valor. Antonio López (2012: 46), afirma que la comunicación de los intangibles es tan estratégica y necesaria como su medición y su gestión. Sin comunicación los intangibles pierden peso en la cadena de valor de una compañía puesto que son bienes activos que necesitan para su desarrollo la dinámica de la Comunicación Corporativa. 
Sin embargo, no únicamente se trata de informar (o comunicar hacia los públicos en su sentido más tradicional) de los intangibles que generan valor en las organizaciones, sino de integrar dichos intangibles en la Dirección de las organizaciones.

Panadero y Tena (2009: 86) consideran que el enfoque estratégico de la Comunicación Corporativa reside en su relación con la Dirección de las empresas y los recursos intangibles. Álvarez Villanueva (2010: 59) también concluye en su tesis que, como los intangibles influyen en la cadena de valor, deben formar parte de la toma de decisiones y tenerse en consideración en la estrategia general de la empresa. Así también lo afirman Kaplan y Norton (2004: 28) al advertir que, como la mayor parte del valor de una empresa reside en su activo intangible, los intangibles son una cuestión estratégica.

El siguiente esquema muestra cuál es la relación entre la Comunicación, los intangibles y las diferentes estrategias competitivas.

Cuadro 3. Relación entre Comunicación Corporativa, Estrategia e Intangibles

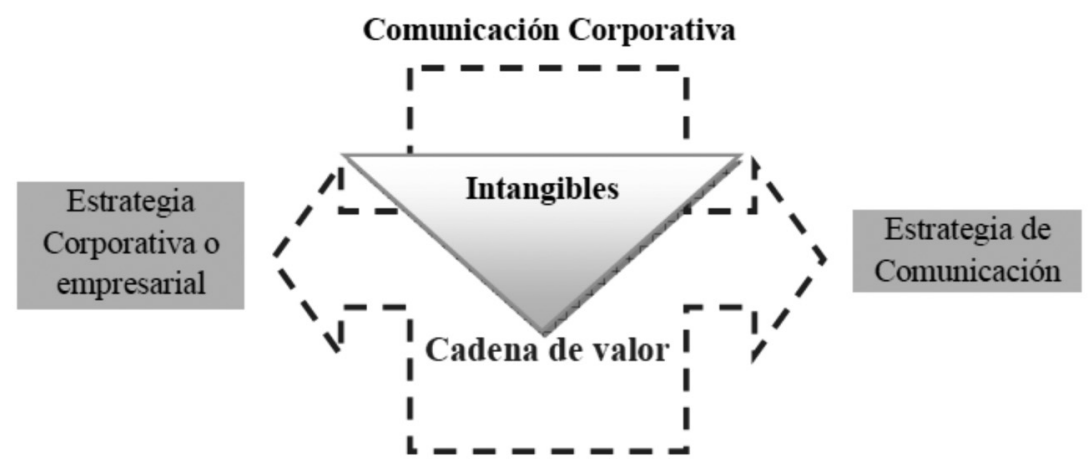

Fuente: Elaboración propia

En conclusión, los intangibles, mediante la Comunicación Corporativa, generan valor en la empresa a través de su inclusión en las estrategias, tanto corporativa/general, como de comunicación.

\section{El nuevo Dircom como gestor de intangibles}

Eduardo Moreno (2002: 111-121) ya señalaba que, en el futuro, la gestión de los activos intangibles iba a ser una tarea profesionalizada que se insertaría en áreas de responsabilidad de la empresa formando parte de las decisiones estratégicas. Como indican Mut y Simón (2005: 63), la gestión de la comunicación y los factores intangibles necesitan de expertos profesionales de la comunicación. La Comunicación Corporativa ha encaminado a la Dirección de Comunicación hacia una 
nueva definición conceptual como departamento intersticial entre la empresa y la sociedad con nuevas tareas fundamentadas en la gestión de intangibles. Se trata de una Dirección de Comunicación de tercera generación.

Cebrián (2009: 64) también señala que el DirCom, actualmente, se ha convertido en un valor en alza que no solo tiene que gestionar la comunicación externa, la interna, asumir la publicidad o el marketing, sino también debe de ser el gestor de los intangibles empresariales.

De igual modo, en el último Anuario de la Comunicación 2012, se señala la evolución que ha sufrido la profesión donde ha pasado de ser una actividad coyuntural a una actividad estratégica y a asumir la gestión de intangibles más allá de la función de la relación con los medios de comunicación (López, 2012: 49).

Como también señalan Gregorio Panadero e Ignacio Tena (2009: 22) las funciones y exigencias de los Directores de Comunicación han evolucionado en los últimos años y ahora son responsables de los recursos intangibles de las compañías. El DirCom del futuro tiene que saber medir y comunicar intangibles. Por lo tanto, su reto será, tanto gestionar los intangibles que se enmarcan bajo la responsabilidad de la Dirección de Comunicación, como dirigir la comunicación corporativa de todo el capital intelectual de la compañía hacia los stakeholders.

En conclusión, el DirCom tendrá que basar la comunicación corporativa de la organización en el abanico de intangibles existentes en la empresa y también gestionar aquellos intangibles que son de su competencia. 
Cuadro 4. Gestión y Comunicación de intangibles en el DirCom

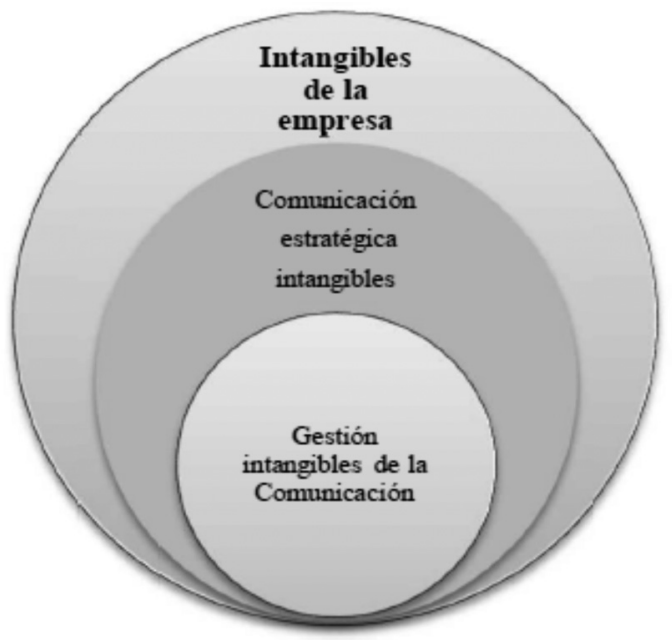

Fuente: Elaboración propia

En consecuencia, y como propone Moreno (2002: 56), la clave para el replanteamiento de la gestión del corporate es tener en cuenta la dimensión estratégica de los activos intangibles; lo que implica un diseño de las direcciones de comunicación con la integración de nuevas funciones en torno a la gestión de activos intangibles mediante:

- $\quad$ La adopción de sistemas de evaluación de intangibles (función investigadora).

- Dotación de instrumentos que orienten la gestión de recursos humanos.

- $\quad$ Adopción de programas de gestión del conocimiento.

- $\quad$ Responsabilidad de la gestión de la comunicación de carácter institucional, esto es, la comunicación global.

- $\quad$ Posición de gestión dependiente de la dirección general.

El corporate es un concepto que, en los años noventa hacía referencia a la gestión estratégica de todos los factores que influyen en la imagen de una organización, por lo que el objetivo era integrar las acciones bajo una misma estrategia. Así, el último salto evolutivo del corporate hace referencia a la gestión de los intangibles empresariales, donde su máxima expresión es la reputación (Villafañe, 2004).

Si tomamos como ejemplo el caso español, el estudio sobre el DirCom y los intangibles realizado por la EOI revela que para el 51,9\% de los DirCom encuestados la gestión de intangibles no está presente entre las principales funciones que la em- 
presa ha fijado para su puesto. El 48,1\% restante sí hace referencia a los intangibles, destacando la gestión de la imagen corporativa, la marca y la reputación. Así, el activo intangible más relevante es la "marca", citada por el 75,3\% de los encuestados. Por detrás se sitúa el "posicionamiento" y la “imagen" (49,4\% y 46,9\%, respectivamente). Además, este estudio revela que el concepto de intangibles es un término reciente, que todavía no está $100 \%$ asentado entre los DirCom. Por lo tanto, en la actualidad, no existe en las direcciones de comunicación un modelo estándar de gestión y reporting de los intangibles y, consecuentemente, no se está aplicando una medición integral de los mismos. Sin embargo, esta falta de familiaridad con el término explica que en ocasiones los DirCom no sean conscientes de que están gestionando intangibles hasta que se describen las funciones asociadas a esta gestión y se dan cuenta de que algunas de ellas sí las desarrollan.

En conclusión, en el plano teórico los DirCom han evolucionado hacia la gestión de intangibles y esta es ahora su función primordial. Sin embargo, ha sido necesaria esta investigación para verificar si actualmente, y en el caso de Reino Unido, el DirCom es o no un auténtico gestor de intangibles.

Adicionalmente, y para apoyar la investigación empírica, parte de la investigación ha consistido en la delimitación, basándose en estudios de referencia en la materia, de cuáles son los activos intangibles de la Comunicación más tradicionales y arraigados en la gestión profesional de la comunicación y estos son: la Marca, la Reputación Corporativa y la Responsabilidad Social Corporativa (RSC). Igualmente, con el marco teórico de la investigación, se ha verificado que los recursos intangibles, que no activos, que se gestionan tradicionalmente desde la Comunicación Corporativa son: la Identidad Corporativa, la Imagen Corporativa y la Cultura Corporativa.

La diferencia entre el concepto activo y recurso únicamente radica en la potencialidad futura (activo) o la imposibilidad (recurso) para reflejarse en el balance de la empresa basándose en la normativa contable vigente. No obstante, esta diferencia no condiciona ni repercute a la existencia o no de su gestión por parte de los Directores de Comunicación. De este modo, la selección de estos activos y recursos intangibles se ha hecho teniendo en cuenta su mayor consideración en los estudios e investigaciones referentes a la Dirección de Comunicación, lo que no quiere decir que el DirCom no pueda o deba gestionar otros intangibles aquí no contemplados. Simplemente, esta previa demarcación ha servido de punto de partida para la investigación empírica posterior.

\section{Principales resultados de la investigación}

La fase de interpretación de las entrevistas ha consistido en una primera etapa de lectura detallada de cada entrevista individual, una segunda etapa de análisis en paralelo de las respuestas individuales de cada profesional a cada pregunta y, por último, la interpretación y reflexión global basándose en los objetivos de la investigación y a cada planteamiento de la investigación empírica, planteamientos que agrupaban en bloques el cuestionario de la entrevista. 
En este apartado se exponen los aspectos generales obtenidos en cada pregunta de la entrevista a partir de la combinación en paralelo de las respuestas de cada uno de los 12 Directores de Comunicación. Con ello, se presentan las principales coincidencias y diferencias respecto a cada pregunta planteada. En este apartado se evita realizar cualquier valoración puesto que el objetivo es la presentación objetiva de los resultados del trabajo de campo.

A continuación se van a exponer los principales resultados de la investigación en torno a dos ítems:

- $\quad$ El perfil del Dircom en Reino Unido y sus funciones principales.

- $\quad$ La gestión de intangibles dentro de la Dirección de Comunicación Corporativa de Reino Unido y tendencias en la materia.

Con relación al primer campo que es objeto de estudio, a los entrevistados se les preguntó sobre la definición y las principales funciones de la figura del Director de Comunicación. La defensa y promoción de la Reputación de la organización, para gran parte de los entrevistados (10/12), se encuentra entre sus principales funciones. De hecho, los pocos profesionales que optan por ofrecer una definición clara de la figura del Director de Comunicación asignan este rol al definir el perfil. Seguidamente, destaca la visión de la gestión de la Comunicación desde la perspectiva de los stakeholders o públicos de interés y/o estratégicos de la empresa. Ya que gran parte de los entrevistados (9/12) indica que uno de sus roles principales se basa en la detección y/o comunicación bidireccional con cada una de sus audiencias o públicos clave. Otra de las funciones a la que más se hace mención es la de la Comunicación interna. Seguidamente se encuentran las relaciones con los medios.

Cuadro 5. Principales funciones del DirCom de Reino Unido

Principales funciones DirCom RU

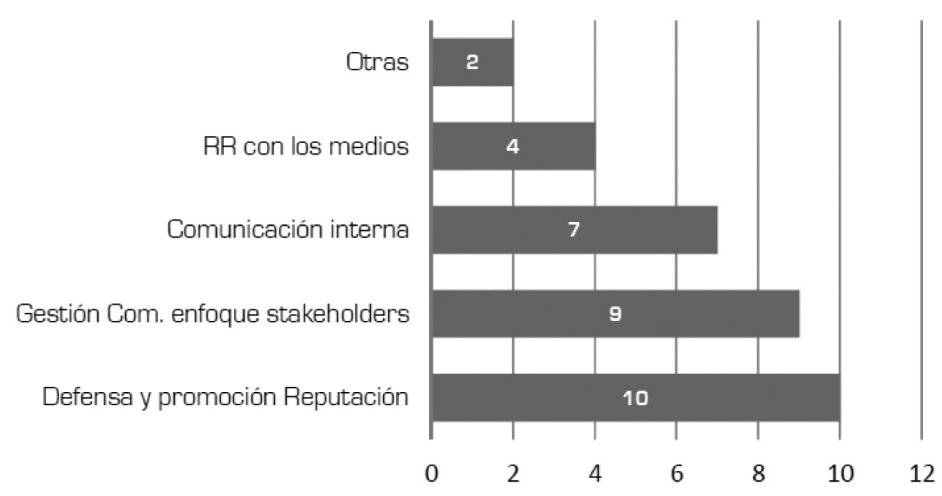

Fuente: Elaboración propia 
Sobre la denominación actual de su cargo, son mayoritarios los casos en que los profesionales ostentan el título de "Director de Comunicación" y además predomina que tengan añadido algún concepto más en dicho título en base a la naturaleza de su puesto de trabajo (Marketing, Asuntos Públicos...). Sobre su satisfacción de acuerdo con la denominación de su cargo, gran parte de los profesionales entrevistados (8/12) indica estar de acuerdo con la denominación actual, mientras que los otros profesionales (4/12) indican que la denominación del puesto de trabajo no es importante puesto que lo relevante son las funciones y lo que realmente se está gestionando.

Además, gran parte de los entrevistados (8/12) piensa que la denominación no va a cambiar. Sin embargo, el interés se encuentra en analizar las razones entre los profesionales que han contestado en el sentido de que "puede que cambie". Destaca que los profesionales que han contestado en sentido positivo a esta pregunta son parte de los mismos profesionales que están de acuerdo con la denominación en la pregunta anterior. Estos profesionales barajan de forma común en cuanto a cambios futuros en la denominación el añadir la parte de "Marketing” y/o la de "Asuntos Corporativos". Además, uno de los entrevistados que forma parte de la muestra apuesta por el mantenimiento de la denominación "Comunicación" como fórmula que engloba adecuadamente todas las funciones y por el cambio de la categoría de "Head" [Jefe] a "Chief Executive" [Director Ejecutivo] o "Director" [Director].

Con relación a la distribución de la gestión de intangibles dentro del Departamento de Comunicación, además de preguntar a la muestra se ha pedido a los profesionales que de forma voluntaria aportaran un organigrama o información de la estructura de su departamento con el objetivo de mejorar la interpretación posterior de la información. Por tanto, los resultados también se han obtenido en base al análisis de los organigramas aportados por los Directores de Comunicación.

En primer lugar cabe destacar cómo todos los entrevistados se consideran responsables de la Reputación y, de estos profesionales, la mitad (6/12) se declara también en parte responsables de la Marca.

La situación mayoritaria es aquella en la que el Director de Comunicación es únicamente responsable de estos intangibles pero además dispone de figuras específicas para su gestión dentro de su Departamento. Sin embargo, muy pocos de ellos dispone de una figura específica para la gestión de un intangible, un "Jefe de Estrategia de Marca". En el resto se trata de una función atribuida a los Directores adjuntos o Subdirectores que reportan al Director de Comunicación, por lo que estos intangibles quedan relegados a un mando intermedio de gestión dentro del Departamento.

En los casos en que la gestión de intangibles se reparte entre el Director de Comunicación y figuras externas al Departamento de Comunicación, claramente destaca que la función de la gestión de Marca se atribuye al Departamento de Marketing.

Por último, cuando la gestión de intangibles se reparte entre el Director de Comunicación, figuras en su Departamento y figuras externas, destaca cómo las figuras ubicadas en el Departamento de Comunicación se encargan más de la Reputa- 
ción y, por su parte la Marca es, de nuevo, competencia de Marketing o de un Director Global de Marca ajeno al Departamento. Todos son responsables de la Reputación y la mitad de los mismos considera que además son también responsables de la Marca. Ninguno de ellos hace mención a la gestión de la RSC.

Cuadro 6. Distribución de la gestión de intangibles

\section{Distribución gestión intangibles II}

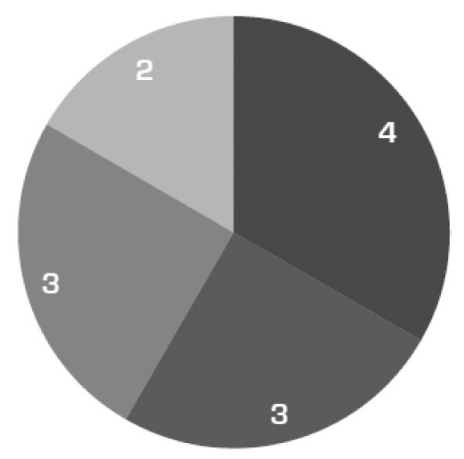

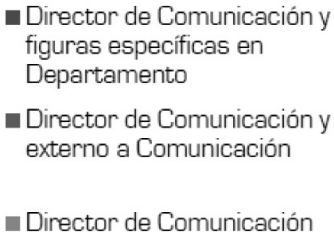

- Director de Comunicación

Director de Comunicación su Departamento y externo

Fuente: Elaboración propia

Si analizamos el esquema de forma global y se suman los casos en los que el Director de Comunicación tiene un papel en la gestión de intangibles, encontramos que el 100\% de los Directores de Comunicación se encarga de la gestión de intangibles aunque existen diferencias en la distribución de dicha gestión. La gestión de la Marca y la Reputación es responsabilidad del Director de Comunicación y de personal específico dentro de su Departamento. Aunque también existen casos en los que es una responsabilidad única del Director de Comunicación o es una responsabilidad repartida entre el Director de Comunicación y áreas externas a Comunicación. Son minoritarios los casos en los que la gestión de estos intangibles se reparte entre el Director de Comunicación, su Departamento, y áreas externas a Comunicación. Cuando se trata de responsabilidades compartidas, destaca que la gestión de la Reputación se ubica más en la parte de Comunicación, y la gestión de Marca en el área de Marketing.

Con referencia al perfil del Director de Comunicación en Reino Unido como una figura estratégica se ha preguntado a los entrevistados por su relación con el CEO de la empresa, su participación en el proceso de toma de decisiones de la empresa o en la definición de la estrategia corporativa.

Los resultados arrojan que poco más de la mitad de los entrevistados (7/12) reportan a estos cargos directivos, y parte de ellos (4/7), indican su reporte directo al CEO de la organización. Un profesional sugiere que el Director de Comunicación 
no reporte únicamente al CEO sino también a una especie de "Director de Operaciones" para las cosas más tácticas a las que el CEO no puede y/o debe dedicar su tiempo. En cambio, el resto de profesionales (5/12) contestan de modo negativo a esta pregunta e indican que reportan a un mando intermediario que se ubica entre él y la Dirección general/CEO.

Los casos en que existe una falta de dependencia directa al CEO de la organización se dan en mayor medida en casos en los que se trata de una firma mundial o global. Además, únicamente hay una figura intermediaria ubicada entre el Director de Comunicación y el CEO.

En adición, gran parte de los entrevistados (8/12) considera que participa en el proceso de toma de decisiones en su organización y los otros (4/12) consideran que no es así.

La participación en el desarrollo de la estrategia corporativa de su organización es menor con relación a la pregunta anterior [participación en decisiones estratégicas $=8 / 12$ ], ya que solo la mitad de los profesionales $(6 / 12)$ contesta en sentido positivo y realiza las siguientes matizaciones:

- $\quad$ Participación en discusiones sobre la Estrategia pero no es miembro de la Junta Directiva.

- $\quad$ Participación en el desarrollo de Estrategia en lo que afecta a Comunicación pero no es miembro del Consejo o la Junta Directiva.

- $\quad$ Participación en la Estrategia solo en lo que puede aportar conocimientos: asuntos de marca, asuntos reputacionales...

Asimismo solo la mitad de estos (3/6) indica claramente su pertenencia al Consejo y/o Junta directiva. Por otra parte, los otros profesionales restantes (6/12) han contestado en sentido negativo con referencia a esta pregunta al considerar que no participan en el desarrollo de la Estrategia Corporativa alegando principalmente la no pertenencia al Comité Dirección, su función anexa a la firma global o su concepción como simple área de apoyo para el desarrollo efectivo de la Estrategia.

Solo la mitad de los Directores de Comunicación participa activamente en la concepción y desarrollo de la Estrategia Corporativa; pero solo la mitad de estos indica pertenecer al Consejo y/o Junta Directiva de su empresa. La otra mitad de profesionales solo se considera como un “facilitador" para la implementación de la Estrategia general de su organización.

A su vez, la mayoría de los Directores de Comunicación (10/12) trabaja bajo una Estrategia de Comunicación que, además, está formalmente documentada. Además la mayoría (11/12) indica que esta deriva directamente de la Estrategia Corporativa de su empresa.

Con relación a que la Comunicación Corporativa ha evolucionado hacia la gestión de intangibles respecto a actividades tradicionales, gran parte de los profesionales entrevistados (8/12) contestan en sentido positivo. 
Respecto a la relación entre la Comunicación y la generación de valor, gran parte de los entrevistados (7/12) de los de Directores de Comunicación considera que la Comunicación es necesaria para que los intangibles generen valor.

Además, parte de esos entrevistados (4/12) afirma que, aunque los intangibles generen valor por sí mismos, la Comunicación ayuda a acrecentar ese valor.

Cuadro 7. ¿Comunicación necesaria para que intangibles generen valor?
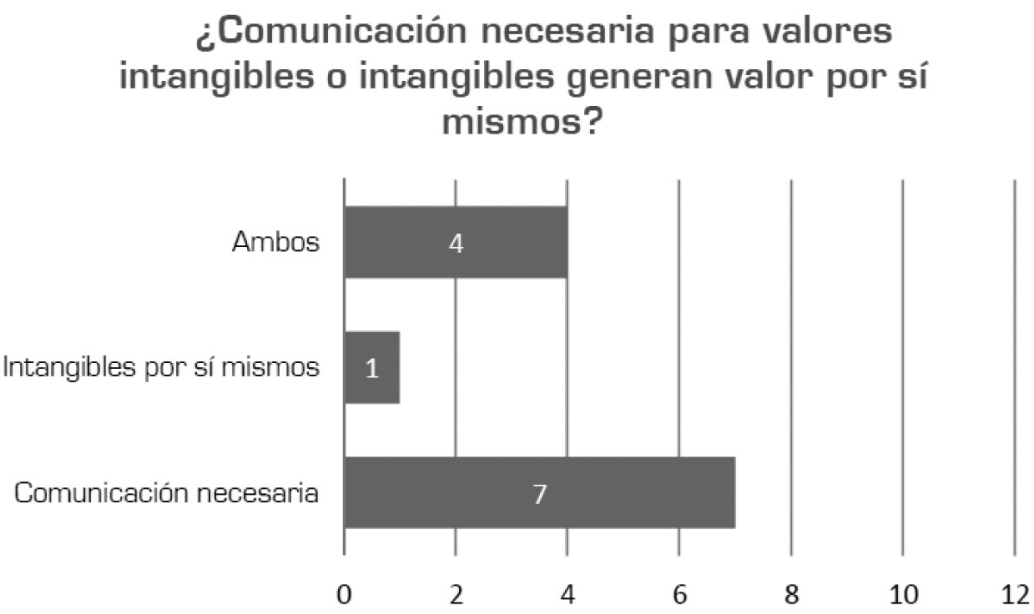

Fuente: Elaboración propia

Con relación a esta cuestión, la mayoría de los Directores de Comunicación (9/12) considera que los intangibles deben formar parte del proceso de toma de decisiones de la empresa para generar valor en la misma. Específicamente, casi todos los Directores de Comunicación (11/12) opinan que los intangibles deben considerarse en la formulación de la Estrategia Corporativa de la empresa y también en la formulación de la Estrategia de Comunicación de la organización $(11 / 12)$.

Con relación al segundo ítem de la investigación y para verificar si el Director de Comunicación en Reino Unido es un auténtico perfil gestor de intangibles, se ha preguntado directamente si gestiona cada uno de los recursos intangibles clásicos en la Dirección de Comunicación: la Identidad Corporativa, la Cultura Corporativa y la Imagen Corporativa.

Con referencia al recurso intangible de la Identidad Corporativa, gran parte de los Directores de Comunicación (10/12) indican ser responsables de la Identidad Corporativa de la empresa. Parte de ellos (3/12) indica que es una responsabilidad compartida con otras funciones como las de Marketing, Comunicación interna o Recursos Humanos, o incluso con el CEO y/o el Consejo. Uno de ellos especifica que la Identidad Corporativa es responsabilidad del Director de Marca. 
Con relación al recurso intangible de la Cultura Corporativa, la situación de la gestión de la Cultura Corporativa está dispersa en casos en que los Directores de Comunicación se consideran responsables de la misma (6/12) [entre los cuales existen situaciones en las que la es una función compartida con otras áreas (3/6)], los casos en los que la Cultura Corporativa es una responsabilidad fuera de Comunicación, normalmente en la función de RRHH (4/12), y, por último, casos aislados que simplemente declaran no ser responsables de la Cultura Corporativa o, de nuevo, la consideran como resultado de la Comunicación.

Con referencia al recurso intangible de la Imagen Corporativa, la mayoría de los Directores de Comunicación (11/12), y en correlación con la gestión de la Identidad Corporativa, indica ser responsables de la Imagen Corporativa de la empresa. Pero parte de estos profesionales (4/12) apunta que su gestión es una responsabilidad compartida con áreas como la de marketing o Directores de Marca.

Cuadro 8. Los Recursos Intangibles de la Comunicación en el Dircom de Reino Unido

Los RI clásicos de la Comunicación en el

DirCom de RU

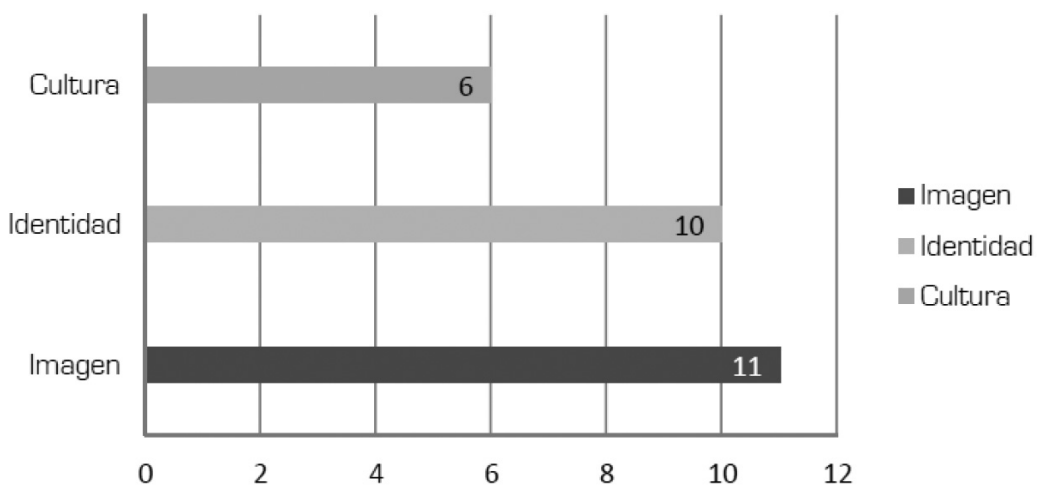

Fuente: Elaboración propia

A partir de la integración de las respuestas se observa cómo, ya sea de forma única, o de modo compartido con otras áreas de la empresa, casi todos los Directores de Comunicación son responsables de la gestión de la Identidad e Imagen Corporativas de su organización aunque es menor la responsabilidad en la gestión de la Cultura Corporativa, que se suele situar en otras áreas de la empresa como la de Recursos Humanos.

Respecto a la consideración de estos recursos intangibles en la Estrategia Corporativa de la empresa, poco más de la mitad de los Directores de Comunicación (7/12), y en igual medida respecto a cada intangible, indican que estos recursos intangibles clásicos de la Comunicación están contemplados en la Estrategia Corporativa de su empresa. 
Por otra parte, la mayoría de los Directores de Comunicación (9/12), y en ligera menor medida en referencia a la Cultura Corporativa, indica que estos recursos intangibles clásicos de la Comunicación forman parte de la Estrategia de Comunicación o, en su defecto, de algún otro documento formal de su departamento.

Igualmente, se les ha preguntado por la gestión de los activos intangibles de la Comunicación más comunes en la Dirección de Comunicación: la Marca, la Responsabilidad Social Corporativa (RSC) y la Reputación Corporativa.

Con referencia al activo intangible de la Marca, todos los Directores de Comunicación (12/12) indican ser responsables de la Marca de la empresa. Pero parte de ellos (4/12) indican que es una responsabilidad compartida con otras funciones como las de Marketing o con el Director de Marca.

Con relación al activo intangible de la RSC, la situación de la gestión está dispersa entre casos en los que los Directores de Comunicación se consideran responsables de la misma (3/12), las situaciones en las que la RSC es una responsabilidad fuera de Comunicación (2/12), las situaciones en que Comunicación tiene un papel en ello pero no es la única función y se comparte entre varias áreas (3/12) y, por último, profesionales que declaran no ser responsables de la RSC (3/12) o que consideran que es responsabilidad de la totalidad de la organización (1/12).

Sobre el activo intangible de la Reputación Corporativa, la totalidad de los Directores de Comunicación (12/12), indica ser responsable de la misma en la empresa. Solo dos profesionales de los que han respondido en sentido afirmativo (2/12) matizan que su gestión es una responsabilidad compartida con otras áreas. También uno de ellos (1/12) advierte que todos en la organización afectan a la Reputación.

Cuadro 9. Los Activos Intangibles derivados de la Comunicación en el DirCom de RU

\section{Los Al derivados de la Comunicación en el}

\section{DirCom de RU}

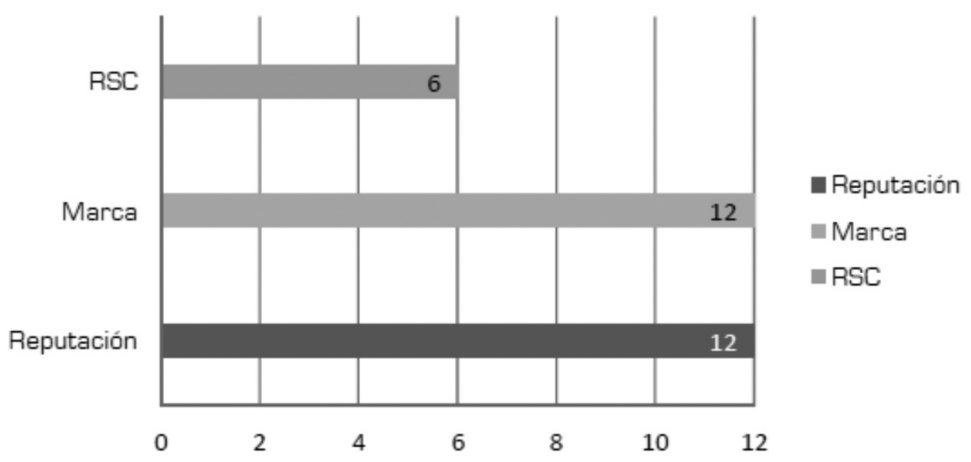

Fuente: Elaboración propia 
A partir de la integración de las respuestas se observa cómo todos los Directores de Comunicación son responsables de la gestión de la Marca y Reputación Corporativas; siendo mayor la responsabilidad única en referencia con el activo intangible de la Reputación sobre el de la Marca, cuya gestión en ocasiones se comparte con otras áreas como la de Marketing. Es menor la responsabilidad en la gestión de la RSC puesto que depende de la estrategia concreta de la organización, si está es/quiere ser socialmente responsable.

Respecto a la consideración de estos activos intangibles en las estrategias de la empresa, poco más de la mitad de los profesionales (7/12), y en igual medida entre activos con una ligera mayor consideración del intangible de la Reputación (8/12), indica que estos activos intangibles derivados de la Comunicación forman parte de la Estrategia Corporativa de su empresa. Con referencia a la Estrategia de Comunicación, la Reputación Corporativa está considerada en la formulación de la misma para la mayoría de los Directores de Comunicación (10/12). La Marca también lo está para gran parte de los casos pero en menor medida respecto a la Reputación (8/12). La RSC solo está considerada en poco más de la mitad de las Estrategias de Comunicación de estos Directores.

En adición, la mayoría de los Directores de Comunicación (9/12) señala que no gestionan ningún otro recurso o activo. Una minoría (3/12) indica que gestiona la Innovación o el Liderazgo, y en todos esos casos es porque esos intangibles forman parte del posicionamiento o Estrategia de su empresa en particular.

Una amplia mayoría de los Directores de Comunicación (9/12) considera que solo deben ser responsables de los recursos y activos intangibles derivados y/o relacionados con la Comunicación. Unos pocos (3/12) piensan que la gestión de los recursos y activos intangibles no se debe realizar solo desde un único lugar o por una única persona, puesto que es una responsabilidad colectiva y del CEO (como apunta uno de ellos) por lo que no se pueden gestionar solo desde un área.

Casi la totalidad de los Directores de Comunicación (11/12) considera que el Director de Comunicación debe tener un amplio conocimiento de todo el abanico de intangibles de la empresa para decidir estratégicamente cuáles comunicar.

La mayoría (9/12) afirma que considera que existe una efectiva integración de la gestión de intangibles en sus funciones como Director de Comunicación. El resto (3/12) indica que no es así, pero la mayoría de estos (2/3) indica que aunque no es así actualmente se están moviendo hacia ello. Por lo que en realidad la respuesta en sentido positivo es ampliamente mayoritaria (11/12).

Sin embargo, una amplia mayoría (11/12) piensa que todavía no puede hablarse de un Director de Comunicación de nueva generación para el cual los intangibles son el centro de su gestión puesto que siguen imperando otras funciones de comunicación. Entre los que piensan así, también existen casos aislados que consideran que siempre ha sido así, que los Directores de Comunicación siempre han gestionado intangibles entre sus funciones. 
Por último, la investigación también contempla la opinión de los Directores de Comunicación de este país sobre las principales tendencias globales en materia de Dirección de Comunicación. Estas son las tendencias de mayor a menor consideración.

Cuadro 10. Tendencias en Dirección de Comunicación

\section{Principales tendencias globales en Dirección} de Comunicación

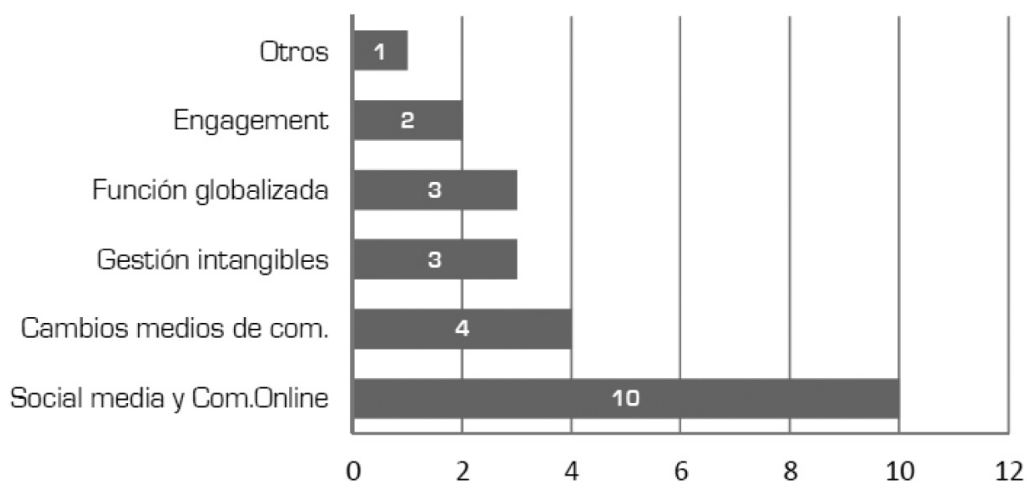

Fuente: Elaboración propia

Como se puede observar, el impacto de las nuevas tecnologías y la emergencia de nuevos canales online hace que la mayoría de los Directores de Comunicación haga especial mención entre las principales tendencias a la gestión de los social media, a su integración a las estrategias y a su consideración por su impacto en la Marca y la Reputación de las organizaciones. En correlación con esto, varios entrevistados señalan los cambios que están por venir en materia de nuevos medios de comunicación. La globalización de la función de Comunicación y el desafío en la gestión de los intangibles empresariales también son preocupaciones comunes en algunos de los Directores de Comunicación entrevistados. La gestión de los Social Media, su integración en las estrategias y el control de su impacto en la reputación y la marca es, por tanto, la principal tendencia en materia de Dirección de Comunicación para los profesionales de Reino Unido.

\section{Conclusiones}

El perfil profesional del Director de Comunicación está consolidado en Reino Unido y se adapta en su denominación a la naturaleza de sus funciones o el sector de la organización a la que pertenece. Por definición, principalmente se encarga de la Reputación y gestiona también otros intangibles desde su área de gestión y/o en colaboración con otras funciones/departamentos. Merece especial atención, tanto por la situación actual del perfil, como por la ten- 
dencia positiva que ello implica, que el intangible más importante y transversal de la empresa, la Reputación Corporativa, forme parte de la definición de la figura y de las funciones principales para el Director de Comunicación de Reino Unido.

Especialmente interesante es también la situación de que, en Reino Unido, la posición del Director de Comunicación y su denominación/título formal, esté completamente adaptada a la naturaleza del puesto de trabajo por lo que se pueden encontrar Directores de Comunicación que además lo son de Marketing o Asuntos Corporativos, entre otros ámbitos. Ello denota la gran flexibilidad de este puesto de trabajo en este país y otorga continuidad y perdurabilidad a esta figura profesional. Asimismo constata la dimensión multidisciplinar de la Comunicación y la obligación de los profesionales a la estructuración y adaptación de sus funciones a los casos particulares a los que se enfrenten.

El Director de Comunicación en Reino Unido es una figura de alta dirección que participa en las decisiones estratégicas de la empresa aunque falte una mayor formalización de su participación con la pertenencia clara a los distintos órganos de Dirección. Destaca cómo, desde una perspectiva práctica, el Director de Comunicación de Reino Unido es claramente una figura estratégica no solo desde el punto de vista orgánico, puesto que reporta, ya sea directa como indirectamente, al CEO de su empresa, sino también desde el punto de vista funcional, puesto que su participación en las decisiones estratégicas de la empresa es elevada. No obstante, demandamos una mayor consideración de la figura del Director de Comunicación de Reino Unido en los órganos directivos a través de una mayor formalización de su participación y su inclusión en el Consejo o Junta Directiva de la empresa puesto que el Director de Comunicación es una figura de alta dirección cuyas decisiones de comunicación, que también tienen una dimensión factual, afectan en gran medida al cómputo total de la organización para la que trabaja por lo que el éxito de la empresa vendrá determinado en mayor o menor medida por el nivel otorgado a esta figura profesional en la escala directiva.

Para el DirCom de Reino Unido los intangibles son factores para la competitividad de las organizaciones pero sigue dando importancia a la dimensión tangible de la empresa.

Los Directores de Reino Unido son conscientes de que la Comunicación Corporativa ha evolucionado hacia la gestión de intangibles y de que la Comunicación es un proceso necesario para la generación de valor a partir de los intangibles; aunque todavía no se conciba totalmente a la propia Comunicación como un recurso intangible en sí misma. Por ello, consideran que se debe informar a los stakeholders sobre los intangibles de la empresa como forma de añadir valor, así como incluir los intangibles en el proceso de toma de decisiones de la empresa con su inclusión en las Estrategias, tanto Corporativa, como de Comunicación, de la empresa.

Específicamente, el Director de Comunicación de Reino Unido gestiona tanto los recursos intangibles clásicos de la Comunicación (Identidad, Imagen y Cultura Corporativas), como los activos intangibles derivados de la Comunicación 
(la Marca, la RSC y la Reputación Corporativa). Por lo que existe una efectiva integración de la gestión de intangibles en sus funciones.

Especialmente, el DirCom de Reino Unido es consciente de que su función clave será conocer la totalidad de intangibles de la empresa para decidir estratégicamente cuáles comunicar.

Estos resultados demuestran que los Directores de Comunicación en Reino Unido gestionan recursos y activos intangibles de la Comunicación por lo que se trata de un perfil gestor de intangibles. Sin embargo, destaca cómo, a pesar de que gestionan activamente intangibles, afirman que estos todavía no son el centro de su gestión puesto que imperan otras funciones tradicionales de la Comunicación Corporativa.

También cabe mencionar que todavía falta una mayor penetración del uso de planes específicos de gestión de intangibles (plan de reputación, plan de marca, programa de RSC, plan de Imagen...etc.) en los Departamentos de Comunicación de Reino Unido.

En adición, no se pueden atribuir intangibles empresariales que no son de su competencia al Director de Comunicación, sin embargo, y como una de las aportaciones de la presente investigación, el papel clave del Director de Comunicación será no solo gestionar los intangibles empresariales de su competencia sino también conocer la totalidad de intangibles de la empresa para decidir estratégicamente cuáles comunicar.

Por otra parte, destaca que la totalidad de los Directores de Comunicación de Reino Unido vean la gestión de los Social Media como el principal reto futuro y también desde el punto de vista de su impacto en los intangibles de la marca y reputación corporativas.

En definitiva, con esta investigación se ha querido demostrar algo que solo se declaraba en el plano teórico y académico, pero que no había sido estudiado ni corroborado desde el punto de vista de la praxis profesional: que la Dirección de Comunicación Corporativa gestiona intangibles empresariales.

Esta investigación demuestra que existe una integración de recursos y activos intangibles en las funciones de los Directores de Comunicación, en este caso, del contexto cultural de Reino Unido, y en la que importantes intangibles empresariales, como son la reputación corporativa o la marca, ya forman parte de las Estrategias y de las más altas decisiones estratégicas de la empresa. Por lo que la figura del Director de Comunicación se establece como pieza fundamental en las organizaciones. 


\section{Referencias bibliográficas}

Álvarez Plaza, J. (2005): Valoración de activos intangibles: El Sistema de Información Empresarial. Disponible en: http://www.ucm.es/info/jmas/finemp/dt/0503.pdf [Consultado el 01/10/2011]

Álvarez Villanueva, C. (2010): Hacia un Nuevo Modelo de Valoración de Intangibles. Disponible en: http://hdl.handle.net/ 10803/10401 [Consultado el 12/II/2013]

Black, S. (2004): ABC de las Relaciones Públicas- Barcelona: Gestión 2000.

Cañibano, L. y Sánchez, M. P. (2004): “Medición, gestión e información de intangibles: lo más nuevo”, Medición, controly gestión de los intangibles, $\mathrm{n}^{\circ} 1, \mathrm{p} .129$.

Casado Molina, A.; Méndiz Noguero, A. y Peláez Sánchez, J. (2013): "The evolution of Dircom: from communication manager to reputation strategist", Communication and Society/Comunicación y Sociedad, vol. XXVI, n. 1, 2013, pp.49-68.

Cebrián, S. (2009): “El dircom, valor empresarial en alza en época de adversidad”, en Anuario de la Comunicación 2009. Madrid: Asociación de Directivos de Comunicación (DirCom), p. 12.

Cornelissen, J. (2011): Corporate Communication. A guide to theory and practice. London: SAGE.

Costa, J. (1999): La Comunicación en acción: informe sobre la nueva cultura de la gestión. Barcelona: Paidós.

- (2003): Imagen corporativa en el siglo XXI. Buenos Aires (Argentina): La Crujía.

- (2010): La Comunicación. 10 voces esenciales. Barcelona: Costa PuntoCom.

- (2011): El ADN del DirCom. Origen, necesidad, expansión y futuro de la Dirección de Comunicación. Barcelona: Costa Punto Com.

Cutlip, S. M., Center, A. H. y Broom, G. M. (2006): Manual de Relaciones Públicas eficaces. Barcelona: Gestión 2000.

Davis, A. (2002): Public relations democracy. Public relations, politics and the mass media in Britain. Manchester: Manchester University Press.

Del Águila, A. R. y Padilla, A. (2002): La Comunicación en la empresa. Un enfoque estratégico. Málaga: Universidad de Málaga.

Dinan, W. y Miller, D. (2000): “The Rise of the PR Industry in Britain, 1979-98”, European Journal of Communication, nº15, pp.5-35.

Gregory, A. (2004): Public Relations in Practice. London: Konan Page - Institute of Public Relations. Disponible en: http://revcom.portcom.intercom.org.br/index.php/cs_um/article/viewFile/4726/4440 [Consultado el: 22/04/2013]

Grunig, J. E. y Hunt, T. (2003): Dirección de Relaciones Públicas. Barcelona: Gestión 2000.

Kaplan, R.S. y Norton, D. P. (2004): Mapas estratégicos: convirtiendo los activos intangibles en resultados tangibles. Barcelona: Gestión 2000, p.31.

54 | n 17, pp. 27-56 | doxa.comunicación 
Kitchen, P. J. y Schultz, D. E. (2001): Raising the Corporate Umbrella. Corporate Communications in the 21st century. Wales: Creative Print and Design.

Koper, E. (2004): “United Kingdom”, en Van Ruler, B. y Vercic, D.: Public relations and communication management in Europe: a nation-by-nation introduction to Public relations Theory and Practice. Berlin: Mouton de Gruyter, pp. 467-485.

Lev, B. (2004): “Intangibles en la encrucijada”, en VV.AA.: Medición, control y gestión de los intangibles. Barcelona: Deusto, pp.15-29.

López, A. (2012): “20 años de DirCom: el prestigio de una profesión”, en Anuario de la Comunicación 2012. Madrid: Asociación de Directivos de Comunicación (DirCom), pp.10-11.

López Lita, R. (1990): Comunicación de las empresas. Las nuevas obligaciones. Madrid: Ciencias Sociales.

- (2000): Comunicación: La clave del bienestar social. Madrid: Drac.

- (2005): “La gestión de intangibles, consolidación de la comunicación corporativa”, en López Lita, R., Fernández Beltrán, F. y Durán, A. (eds.): La comunicación corporativa en el ámbito local. Castellón de la Plana: Publicacions de la Universitat Jaume I, pp. 55 y 56.

Lucas Marín, A. (1997): La Comunicación en la empresa y en las organizaciones. Barcelona: Bosch.

Matilla, K. (2010): “Pasado, presente y futuro del 'DirCom’ en España”, Revista FISEC-Estrategias, no 14, Volumen 4, pp.324. Disponible en: http://www.cienciared.com.ar/ra/doc.php?n=1359 [Consultado el: 10/I/ 2011].

Martín Martín, F. (2010): Comunicación empresarial (corporativa) e institucional: business corporate and institutional communication. Madrid: Universitas.

Moreno, E. (2002): “Panel Delphi: el futuro del corporate en España”, en Villafañe, J. (Dir.): El Estado de la publicidad y el corporate en España: informe anual. Madrid: Pirámide, pp.98-110.

Mut Camacho, M. y Simón Delgado, R. (2005). “El director de comunicación: ¿̨horizonte nítido o borroso?”, en Revista FisecEstrategias, $\mathrm{n}^{\circ}$ 1. Disponible en: http://www.fisec-estrategias.com.ar/1/fec_01_com_mut.pdf [Consultado el: 20/IX/2010]

Nevado, D. y López, V. R. (2002): El capital intelectual: Valoración y medición. Madrid: Pearson Educación, p. 53.

Oliver, S. (2010): Public Relations Strategy. London: Konan Page.

Panadero, G. y Tena, I. (2009): “Estudio del arte: qué son los intangibles del DirCom”, Anuario de la Comunicación 2009. Madrid: Asociación de Directivos de Comunicación (DirCom), pp.64-65.

Pérez, R. A. (2008): Estrategias de Comunicación. Barcelona: Ariel.

Pizzolante, I. (1999): Reingeniería del pensamiento. Caracas: Panapo.

- (2009): De la Responsabilidad Social Empresarial a la Empresa Socialmente Responsable. Madrid: Ciencias sociales. 
Somerville, I. (2004): "Public relations, politics and the media”, en Theaker, A. (ed.): The Public Relations Handbook. London: Routledge, pp.32-47.

Sotelo, C. (2001): Introducción a la Comunicación Institucional. Barcelona: Ariel.

Van Riel, Cees B.M. (1997): Comunicación Corporativa. Madrid: Prentice Hall.

Van Ruler, B. y Vercic, D. (2004): Public relations and communication management in Europe: a nation-by-nation introduction to Public relations Theory and Practice. Berlín: Mouton de Gruyter, pp. 467-485.

Villafañe, J. (1993): Imagen positiva: Gestión estratégica de la imagen de las empresas. Madrid: Pirámide.

- (2006): Quiero trabajar aquí: las seis claves de la reputación interna. Madrid: Pearson Educación.

VV.AA (2002): Directrices para la gestión y difusión de información sobre intangibles: informe de capital intelectual. Madrid: Fundación Airtel Móvil.

VV.AA. (2010): Nuevos modelos de gestión y función de los responsables de comunicación. Estudio sobre el modelo de gestión y reporting de intangibles para un Dircom. Madrid: EOI. Disponible en: http://www.eoi.es/savia/pubman/item/eoi:39060:3 [Consultado el 15/II/2012]

VV.AA. (2011): European Communication Monitor 2011. Empirical Insights into Strategic Communication in Europe. Results of an Empirical Survey in 43 Countries (Chart Version), Bruselas: EACD y EUPRERA. Disponible en: http://www. communicationmonitor.eu [Consultado el: 1/IX/2011]

VV.AA. (2012): European Communication Monitor 2012. Challenges and Competencies for Strategic Communication. Results of an Empirical Survey in 42 Countries. Bruselas: EACD y EUPRERA. Disponible en: http://www. communicationmonitor.eu [Consultado el: 5/VII/2012]

White, J., L'Etang, J. y Moss, D. (2009): “The United Kingdom: advances in practice in a restless Kingdom”, en Sriramesh, K. y Vercic, D. (Eds.): The Global Public Relations Handbook. Theory, Research, and Practice. London: Routledge, cap.19. 